UC-28

Issued: January 1988

\title{
A Ring Model of the Lasertron
}

LA--11189-MS

Paul J. Tallerico

DE88 004656

\author{
Jean-Pierre Coulon*
}

\section{DISCLAIMER}

This report was prepared as an account of work sponsored by an agency of the United States Government. Neither the United States Government not any agency thereof, nor any of their employees, makes any warranty, express or implied, or assumes any legal liability or responsibility for the accuracy, completeness, or usefulness of any information, apparatus, product, or process disclosed, or represents that its use would not infringe privately owned rights. Reference herein to any specific commercial product, process, or service by trade name, trademark, manufacturer, or otherwise does not necessarily constitute or imply its endorsement, recommendation, or favoring by the United States Government or any agency thereof. The views and opinions of authors expressed herein do not necessarily state or reflect those of the United States Government or any agency thereor.
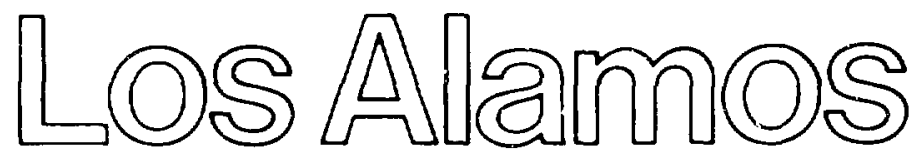


\title{
A RING MODEL OF THE LASERTRON
}

\author{
by \\ Paul J. Tallerico and Jean-Pierre Coulon
}

\begin{abstract}
A large-signal, $2-1 / 2$ dimensional relativistic particle dynamics corle has been written to simulate the electrical behavior of the lasertron. The theory and the approximations involved in this code are discussec. in detail. Numerical results are presented to slow the comparison with previous work and to show the general variation in lasertron performance with frequency, beam voltage, and beam current. 'The code has also been used to design a prototype 6- $\mathrm{CHHz}$ lasertion for construction at the Laboratoire de l'Accólérateur Linéaire in Ursay, France. The calculations show that this prototype can produce 4.T-MW peak-power oulput with a conversion efficiency of $65 \%$. At $3 \mathrm{GHz}$, the power would be increased by a factor approaching 10 , and the conversion efficiency would be over $\tau 0 \%$.
\end{abstract}

\section{INTRODUCTION}

The lasertron is a device to transform high-voltage power to microwaves, and it is much like a klystron with a photocathode. The beam is muched in the lasert ron by the laser light that is modulated at the microwave frequency. The photoelectmons are produced at a cathode (see Fig. 1) and are accelerated to a fairly high voltage in the guu region by an electric field. These electrons produce microwaves in the output saction, which is one or more cavities that decelerate the beam with the microwave fields. Wilh the present availability of powerful lasers with picosecond light pulses, there is little donht that this device can be an efficient microwave generator at frequencies below 1 or $2 \mathrm{CiHz}$, but the debunching electron dynamics are quite complicated; thus, the npper frequency linits are not well defined. This report discusses a computer model of the lasertron. This modiel 
can be used to predict general trends of lasertron performance, dependent on llie device paranneters, and the model can also be used to design lasertrons for particular applications.

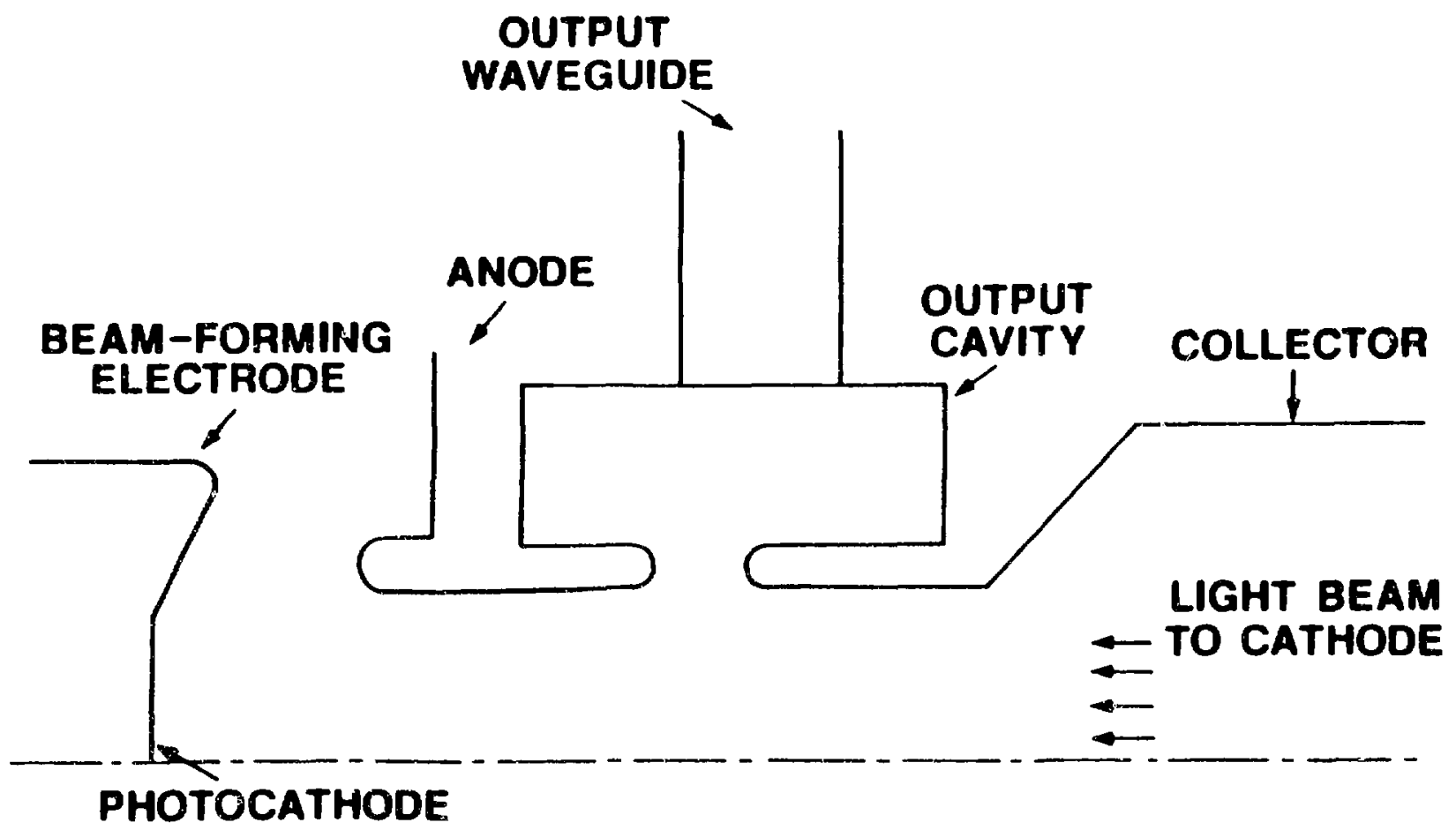

Fig. 1. Schenatic diagran of a lasertron.

Codes for the ring-and-clisk model of the elect.rolynanics in the klyst ron have recently been writien. 1,2,3 'These codes have been tested with two types of 1.25-MW k!yst.rons used at Los Alanos and with the Stanford Lineas Accelerator ('enter (SLAC) 50-MW klystron; good agreement was obtained between predicted and actual operation of the electronic efficiency and the power-transler characteristics. 'I'hese klystrons had do to rf couversion efficiencies of between 50 and $60 \%$. A similar program inas been written to study the lasertron interaction. The main features of the ring model of the lasert ron are described below.

The relativistic electron cignamics of a set of particles are fillowed from the pliotocathode throngh the gun region and through the output region. with time as the independent variable. The fields are summed by superposition to fi:al the total field at each electron's position. The nortel is $2.1 / 2$ dimensional, becanse $r$ and $z$ are trackerl for earl paiticle. but "s is obtajned from the relativistic form of Busch's theorem. Wake lields and the transient filling of the output cavity are ignored. A single bumblo of edectums is followed through the lasertron, but the corle can easily be modified to calculate the dynamics of a small number of bunches at the expense of computer time.

The program is modular and flexible; therefore, many of lie fields can be apuroximated in several ways to alter the accuracy and time recpinements to perform the simulatirm. In several instances, the work is not complete in that the varions approxinations have not all been carried ont. In each field calculation, the copuations that have been progrannuled 
are described, and other alternatives will be described that could be used to speed up the execution time or to improve the overall accuracy.

For the examples in this report, the particles all have the sante charge; thus, the laser light pulse is assumed to be rectangular. This restriction has recently been removed to allow trapezoidal, Ciaussian, or arbitrary light pulses to be simulated. All processes in the photocathode are assumed to be instantaneous. The beam model is a central disk surrounded by rings. This combination starts at the cathode in a plane and is repeated many times over the length of the laser pulse. Typically, between 20 and 200 particles are follow $J$, and between 0.5 and 50 minutes of VAX 11/785 time are needed to do a simulation. A separate graphical ont put program may be run to obtain the pictures of the interaction. The stalic electric fields in the gun region have both $E_{r}$ and $E_{z}$ components, and the static magnetic fieids have $B_{r}$ and $B_{z}$ components. Both the space-charge and the output-cavity fields liave $E_{r}, E_{z}$, and $B_{\varphi}$ components.

\section{EQUATIONS OF MOTION}

Starting with the Lorentz force and the energy conservation equations 4

$$
\frac{d}{d t}\left(m_{0} \gamma \vec{v}\right)=\epsilon(\vec{E}+\vec{v} \times \vec{B})
$$

and

$$
\frac{d}{d t}\left(m_{0} \gamma c^{2}\right)=\epsilon \vec{v} \cdot \vec{E}
$$

(with the following normalizations:

$$
\begin{aligned}
T & =\omega t, \\
\vec{v} & =\vec{v} / u_{0}, \\
u_{n} & =u_{0} / c, \\
\eta & =|\epsilon| / m_{0}, \\
R & =\omega r / u_{0}, \text { and } \\
Z & \left.=\omega z / u_{0}\right),
\end{aligned}
$$

one finds that the force equations in cylindrical coordinates are

$$
\frac{d l_{z}^{r}}{d \tau}=\frac{-\eta}{\omega \gamma}\left\{\frac{E_{z}}{u_{0}}\left[1-\left(u_{n} l_{z}\right)^{2}\right]-\eta_{\zeta} B_{r}+V_{r}\left(B_{\phi}-u_{n} V_{z} E_{r} / c\right)\right\}
$$

and

$$
\frac{d V_{r}^{r}}{d \tau}=\frac{-\eta}{\omega \gamma}\left\{\frac{E_{\tau}}{u_{0}}\left\{1-\left(u_{n} V_{r}\right)^{2}\right\}+V_{\phi} B_{z}-V_{z}\left(B_{\phi}+u_{n} V_{r} E_{z} / r\right)\right\}+V_{\phi}^{2} / R,
$$

where the velocities have been normalized to $u_{0}$, the velocity of an electron on the axis and at the anode voltage. The equation for the conservation of angular noment um is

$$
l_{j}=\frac{\eta R_{i} B_{z}}{2 \omega \gamma}\left(1 \quad \frac{R_{c}^{2} B_{z c}}{R^{2} B_{z}}\right),
$$


and the energy equation is

$$
\frac{d \gamma}{d \tau}=-\frac{\eta u_{n}}{c \omega}\left(E_{r} V_{r}+E_{z} V_{z}\right)
$$

Of course, $\gamma$ is also given by

$$
\gamma=\left[1-u_{n}^{2}\left(V_{r}^{2}+V_{\phi}^{2}+V_{z}^{2}\right)\right]^{-1 / 2} .
$$

T'he $\gamma$ 's are calculated by Eqs. ( 7 ) and (8), and the difference is used to estimate the integration errors. The new posilions are found from the velocities

$$
Z=\int V_{i} d \tau
$$

and

$$
R=\int V_{r} d \tau
$$

The equations of motion, Ecss. (1) to (10), are numerically solved by the Euler melhod with $\tau$ as the independent variable.

There are a variable number of particles in the program. After the beam is injected, there are $N_{z}$ axial slices, with $N_{r}$ rings in each slice. At each time step within the laser pulse, the subroutine TESTNEW determines if a new set of $N_{r}$ particles should be emitted at the calliode. When the laser pulse is over, a total of $N_{r} N_{z}$ particles will have been emitted. These electrons all starl wilh zero velncity and are positioned on the cathode so that each particle represents equal charge. Thus, thermal velocity effects are neglected, and the bean initially has zero emittance.

\section{ELECTROMAGNETIC FIELDS}

The calculation of the field components is the most difficult task in the simulation. The philosophy is to integrate the other programs of the electron dynamics community and to use their outpul as input data for the lasertron program. Thus, the gun's static electric fields may be calculated with Hermannsfeldt's gun progran, ${ }^{5}$ the cavity fields calculated with SUPERFISH, ${ }^{6}$ and the magnetic focus fields calculated with POISSON. ${ }^{7}$

\section{SPACE-CHARGE FIELDS}

Because the buncl changes its sliape so quickly in the lasert ron, the space-charge forces must be evaluated at every time step. The first action taken by the space-charge routine CHADESPAC is to set the five field components $E_{r}, E_{z}, B_{r}, B_{z}$, and $B_{\phi}$ to zero. At present there are three methods that may be used to calculate the space-charge fields: the ring model, a one-dimensional disk methorl, and a two-dimensional approximate model. All these methods are Green function methods; hence, the computation time varies as the square of the numbirs of particles. One expects that the use of a finite-difference or finite-element computation and a fast Fourier transform method would significantly 
reduce the space-charge computation time for large number of particles because this type of computation takes a time proportional $1.0 \mathrm{n} \log \mathrm{n}$.

The ring Cireen function method has been tested by varying the number of rings and slices in a beam and checking the space-charge ficlds for a bean of constanl velncity. The essence of the method ${ }^{8}$ is to solve Laplace's equation for a ring (or disk) of clarge tlat is surrounded by a perfectly conducting drift tube. The potential in the rest frame of the ring is

$$
\tilde{\Phi}\left(r, \tilde{z} ; r^{\prime}, \tilde{z}^{\prime}\right)=\sum_{n=1}^{\infty} \frac{J_{0}\left(\nu_{n} r\right) J_{0}\left(\nu_{n} r^{\prime}\right)}{\nu_{n} a^{2} J_{1}\left(\nu_{n} a\right)^{2}} \exp \left(-\nu_{n}\left|\tilde{z}-\tilde{z}^{\prime}\right|\right)
$$

and

$$
\tilde{\vec{A}}\left(r, \tilde{z} ; r^{\prime}, \tilde{z}^{\prime}\right)=0
$$

where $\mathrm{r}^{\prime}, \tilde{z}$ are the coordinates of the observation point, and $r^{\prime}, \tilde{z}^{\prime}$ are the coordinates of the source point of the ring of charge $q$ inside the drift tumbel of radius a. The tildes denote quantities that will change under a Lorentz transformation. The eigenvalues are the solutions of

$$
J_{0}\left(\nu_{n} a\right)=0
$$

where $a$ is the radius of the drift tube. The fields in the lalsoratory frame are found loy a Lorentz transformation using the source particle's $z$ velocity. The covariant four vectors

$$
\Phi^{i}=(c \vec{A}, \Phi)
$$

and

$$
x^{i}=(x, y, z, t)
$$

both transform as $\Phi^{j}=Q_{i}^{j} \phi^{i}$ and $x^{j}=Q_{i}^{j} x^{i}$, where

$$
Q_{i}^{j}=\left(\begin{array}{cccc}
1 & 0 & 0 & 0 \\
0 & 1 & 0 & 0 \\
0 & 0 & \gamma & \beta \gamma \\
0 & 0 & -\beta \gamma & \gamma
\end{array}\right)
$$

and $Q_{1}^{j}$ is the transformation matrix from the beam frame to the laboratory frame, $v_{z}$ is the axial velocity of the source electron, $\beta=v_{;} / c$, and $\gamma=\left(1-\beta^{2}\right)^{-1 / 2}$. The potentials in the lalsoratory frame are then

$$
\Phi\left(r, z ; r^{\prime}, z^{\prime}\right)=\frac{\gamma}{2 \pi \epsilon_{0}} \sum_{n=1}^{\infty} \frac{J_{0}\left(\nu_{n} r\right) J_{r}\left(\nu_{n} r^{\prime}\right)}{\nu_{n} a^{2} J_{i}^{(}\left(\nu_{n} a\right)} \exp \left(-\nu_{n} \gamma\left|z-z^{\prime}\right|\right)
$$

and

$$
\left.\left.\vec{A}\left(r, z ; r^{\prime}, z^{\prime}\right)=\frac{\hat{z} v^{\prime} z \gamma}{2 \pi \epsilon_{0} c^{2}} \sum_{n=1}^{\infty} \frac{J_{0}\left(\nu_{n} r\right) \cdot J_{0}\left(\nu_{n} r^{\prime}\right)}{\nu_{n} a^{2} J_{1}^{2}\left(\nu_{n} a\right)} \exp \right)\left(-\nu_{n}\right)\left|z-z^{\prime}\right|\right)
$$


The laboratory frame fields are found from the potentials as

$$
\begin{gathered}
E_{r}\left(r, z ; r^{\prime}, z^{\prime}\right)=\frac{\gamma}{2 \pi \epsilon_{0} a^{2}} \sum_{n=1}^{\infty} \frac{J_{1}\left(\nu_{n} r\right) J_{0}\left(\nu_{n} r^{\prime}\right)}{J_{1}^{2}\left(\nu_{n} a\right)} \exp \left(-\nu_{n} \gamma\left|z-z^{\prime}\right|\right), \\
E_{z}\left(r, z ; r^{\prime}, z^{\prime}\right)=\frac{\operatorname{sgn}\left(z-z^{\prime}\right)}{2 \pi \epsilon_{0} a^{2}} \sum_{n=1}^{\infty} \frac{J_{0}\left(\nu^{\prime}, r\right) J_{0}\left(\nu_{n} r^{\prime}\right)}{\frac{\prime_{1}^{2}\left(\nu_{n} a\right)}{\nu^{\prime}} \exp \left(-\nu_{n} \gamma\left|z-z^{\prime}\right|\right),}
\end{gathered}
$$

and

$$
B_{\phi}\left(r, z ; r^{\prime} z^{\prime}\right)=\frac{n^{\prime} z}{c^{2}} \vec{z}_{r}\left(r, z ; r^{\prime} z^{\prime}\right) \text {. }
$$

The total space-charge fields are found by integrating the Green functions times the charge density over the volume occupied by the beam.

$$
\vec{E}_{s c}(r, z)=\iiint \rho^{\prime}\left(V^{\prime}\right) \vec{E}\left(r, z, ; r^{\prime} z^{\prime}\right) d V^{\prime}
$$

where $\rho^{\prime}\left(V^{\prime \prime}\right)$ is the charge density in the beam. The Green functions for the $z^{\prime} \cdot$-volume sources become infinite as one approaches the singularity, so it is prudent to use a finite volume source as the Green function. Consider the beann when all of it is moving with the axial velocity $u_{0}$, which corresponds to $V_{0}$, the vollage on the axis after the gun region. Each ring is given an axial extent of $L_{0} / N_{z}$ and a radial extent dr so that the beam volume is exactly filled. The term $L_{0}$ is the distance the beam travels in one if cycle when the beam velocity is $u_{0}$. It is more convenient to define the normalized Green functions by the relations

$$
E_{r}\left(r, z ; r^{\prime} z^{\prime}\right)=\frac{\gamma}{2 \pi \epsilon_{0} a^{2}} F_{2 r}\left(r, z ; r^{\prime}, z^{\prime}\right)
$$

and

$$
E_{z}\left(r, z ; r^{\prime} z^{\prime}\right)=\frac{\operatorname{sgn}\left(z-z^{\prime}\right)}{2 \pi \epsilon_{0} \mathrm{a}^{2}} F_{2 z}\left(r, z ; r^{\prime}, z^{\prime}\right)
$$

By integrating the normalized functions as described above, one finds the expressions ${ }^{3}$

$$
\begin{aligned}
& \bar{F}_{2 r}\left(r, z ; r^{\prime}, z^{\prime}\right)= \\
& \sum_{n=1}^{\infty} \frac{2}{\left(r^{\prime}+d r\right)^{2}-\left(r^{\prime}-d r\right)^{2}}\left\{\left(r^{\prime}+d r\right) J_{1}\left[\nu_{n}\left(r^{\prime}+d r\right)\right]-\left(r^{\prime}-d r\right) J_{1}\left[\nu_{n}\left(r^{\prime}-d r\right)\right]\right\} \\
& \left\{\exp -\left[\gamma \nu_{n}\left(\left|z-z^{\prime}\right|-L_{0} / 2 N_{z}\right)\right]-\exp \left[-\gamma \nu_{n}\left(\left|z-z^{\prime}\right|+L_{0} / 2 N_{z}\right)\right]\right\} \frac{N_{z}\left(\nu_{n} r\right)}{\gamma L_{0} \nu_{n}^{2} J_{1}^{2}\left(\nu_{n} a\right)},
\end{aligned}
$$


and

$\bar{F}_{2 z}\left(r, z ; r^{\prime}, z^{\prime}\right)=$

$$
\begin{gathered}
\sum_{n=1}^{\infty} \frac{2}{\left(r^{\prime}+d r\right)^{2}-\left(r^{\prime}-d r\right)^{2}}\left\{\left(r^{\prime}+d r\right) J_{1}\left[\nu_{n}\left(r^{\prime}+d r\right)\right]-\left(r^{\prime}-d r\right) J_{1}\left[\nu_{n}\left(r^{\prime}-d r\right)\right]\right\} \\
\left\{\exp -\left[\gamma \nu_{n}\left(\left|z-z^{\prime}\right|-L_{0} / 2 N_{z}\right)\right]-\exp \left[-\gamma \nu_{n}\left(\left|z-z^{\prime}\right|+L_{0} / 2 N_{z}\right)\right]\right\} \frac{N_{z} J_{0}\left(\nu_{n} r\right)}{\gamma L_{0} \nu_{n}^{2} J_{1}^{2}\left(\nu_{n} a\right)}
\end{gathered}
$$

for $\left|z-z^{\prime}\right|>L_{0} / 2 N_{z} ;$ likewise for the other region,

$\bar{F}_{2 r}\left(r, z ; r^{\prime}, z^{\prime}\right)=$

$$
\sum_{n=1}^{\infty} \frac{2}{\left(r^{\prime}+d r\right)^{2}-\left(r^{\prime}-d r\right)^{2}}\left\{\left(r^{\prime}+d r\right) J_{1}\left[\nu_{n}\left(r^{\prime}+d r\right)\right]-\left(r^{\prime}-d r\right) J_{1}\left[\nu_{n}\left(r^{\prime}-d r\right)\right]\right\}
$$

$$
\left\{2-\exp \left[-\gamma \nu_{n}\left(\left|z-z^{\prime}\right|+L_{0} / 2 N_{z}\right)\right]-\exp \left[\gamma \nu_{n}\left(\left|z-z^{\prime}\right|-L_{0} / 2 N_{z}\right)\right]\right\} \frac{N_{z} J_{1}\left(\nu_{n} r\right)}{\gamma L_{0} \nu_{n}^{2} J_{1}^{2}\left(\nu_{n} a\right)}
$$

and

$\bar{F}_{2:}\left(r, z ; r^{\prime}, z^{\prime}\right)=$

$$
\begin{gathered}
\sum_{n=1}^{\infty} \frac{2}{\left(r^{\prime}+d r\right)^{2}-\left(r^{\prime}-d r\right)^{2}}\left\{\left(r^{\prime}+a^{\prime} r\right) J_{1}\left[\nu_{n}\left(r^{\prime}+d r\right)\right]-\left(r^{\prime}-d r\right) J_{1}\left[\nu_{n}\left(r^{\prime}-d r\right)\right]\right\} \\
\left\{\exp \left[\gamma \nu_{n}\left(\left|z-z^{\prime}\right|-L_{0} / 2 N_{z}\right)\right]-\exp -\left[\gamma \nu_{n}\left(\left|z-z^{\prime}\right|+L_{0} / 2 N_{z}\right)\right]\right\} \frac{N_{z} J_{0}\left(\nu_{n} r\right)}{\gamma L_{0} \nu_{n}^{2} J_{1}^{2}\left(\nu_{n} a\right)}
\end{gathered}
$$

for $0<\left|z-z^{\prime}\right|<L_{0} / 2 N_{z}$. The finite-volime normalized Green functions, Eqs. (24)-(27), are the ones used in the progran for the Bessel function space-charge option. The second method is the one-dimensional disk method, which has the advantage of being very quick, but it is the least accurate space-charge field method. The potential on the axis of a disk of radius $r^{\prime}$ and position $\bar{z}^{\prime}$ is known as

$$
\bar{\Phi}\left(0, \tilde{z} ; r^{\prime}, \tilde{z}^{\prime}\right)=\frac{q}{2 \pi \epsilon_{0} r^{\prime 2}}\left[\sqrt{\left(\bar{z}-\tilde{z}^{\prime}\right)^{2}+r^{\prime^{2}}}-\left|\tilde{z}-\tilde{z}^{\prime}\right|\right]
$$


in the beam frame. The axial field in the beam frame is therefore

$$
\tilde{E}_{z}\left(0, \bar{z} ; r^{\prime}, \tilde{z}^{\prime}\right)=\frac{q \operatorname{sgn}\left(\tilde{z}-\tilde{z}^{\prime}\right)}{\pi \epsilon_{0} \mathrm{r}^{\prime 2}}\left[1-\frac{\left|\tilde{z}-\tilde{z}^{\prime}\right|}{\sqrt{\left(\tilde{z}-\tilde{z}^{\prime}\right)^{2}+r^{\prime 2}}}\right],
$$

and this transforns into the laboratory frame as

$$
E_{z}\left(0, z ; r^{\prime}, z^{\prime}\right)=\frac{q \operatorname{sgn}\left(z-z^{\prime}\right)}{\pi \epsilon_{0} \mathbf{r}^{\prime 2}}\left[1-\frac{\gamma\left|z-z^{\prime}\right|}{\sqrt{\gamma^{2}\left(z-z^{\prime}\right)^{2}+r^{\prime 2}}}\right] .
$$

One can also calculate the transverse field components in the laboratory frame, but these are neglected in this one-dimensional approxinntion.

The third method for the space-charge fields is called the economic two-dimensional method, so called because it also is approximate but is economical wilh computer time. This method is relativistically correct to first order because the fields are calculated electrostatically in the beam frome of reference. Each source ring is treated as a ring for the innermost observer rings, as a charge ribbon for intermediate cases, and as a point charge for the outernost observation rings. Different approximations are used in the output region to approximately include the radial boundary condition in the output region: $E_{z}$ is neglected and $E_{m}$ is assumed to follow Causs's law. It is the only method programmed to date that has the images of the charges in the cathode plane. This is the method that has been used for most of the calculations with large numbers of particles as it is about 10 times faster than the Bessel function method. In the laboratory frame, the axial field in the gun region is

$$
E_{z}\left(r, z ; r^{\prime}, z^{\prime}\right)=\frac{q\left(z-z^{\prime}\right)}{4 \pi \epsilon_{0}\left[\gamma^{2}\left(z-z^{\prime}\right)^{2}+r^{\prime 2}\right]^{3 / 2}}
$$

for $r<r^{\prime}$

$$
E_{z}\left(r, z ; r^{\prime}, z^{\prime}\right)=\frac{q}{A_{r} \pi \epsilon_{0}} \arctan \frac{d r}{2 \gamma\left(z-z^{\prime}\right)}
$$

for $r \simeq r^{\prime}$, and

$$
E_{z}\left(r, z ; r^{\prime}, z^{\prime}\right)=\frac{q\left(z-z^{\prime}\right)}{4 \pi \epsilon_{0}\left[\gamma^{2}\left(z-z^{\prime}\right)^{2}+r^{2}\right]^{3 / 2}}
$$

for $r>r^{\prime}$, where $A_{r}$ is the area of the washer. The corresponding raclial electric field is

$$
E_{r}\left(r, z ; r^{\prime}, z^{\prime}\right)=0
$$

for $r$ an inner ring,

$$
E_{r}\left(r, z ; r^{\prime}, z^{\prime}\right)=\frac{q}{4 \pi \epsilon_{0}} \overline{\left[r_{i}^{2}+\gamma^{2}\left(z-z^{\prime}\right)^{2}\right]^{3 / 2}}
$$

for all other $r$, where $r_{e}$ is the maximum of $r, r^{\prime}$, and the magnetic field is given by Eq. (20). 
There are at least three major improvements that are bejing considered for the spacecharge fields. The first is to use the Circen function for a ring of charge in a cylindrical box? in the gun region

$$
\tilde{\Phi}\left(r, \tilde{z} ; r^{\prime}, \tilde{z}^{\prime}\right)=\frac{1}{\pi c_{0} a^{2}} \sum_{n=1}^{\infty} \frac{\sinh \left(\nu_{n} \tilde{z}\right) \sinh \left[\nu_{n}\left(\tilde{z}_{a}-\tilde{z}\right)\right]}{\sinh \left(\nu_{n} \tilde{z}_{a}\right)} \frac{J_{0}\left(\nu_{n} r^{\prime}\right) J_{0}\left(\nu_{n} r\right)}{\nu_{n}, J_{1}^{2}\left(\nu_{n} a\right)}
$$

for $\bar{z}<\bar{z}^{\prime}$, and

$$
\tilde{\Phi}\left(r, \tilde{z} ; r^{\prime}, \tilde{z}^{\prime}\right)=\frac{1}{\pi \epsilon_{0} a^{2}} \sum_{n=1}^{\infty} \frac{\sinh \left[\nu_{n}\left(\tilde{z}_{a}-\tilde{z}\right)\right]}{\sinh \left(\nu_{n}\right)} \frac{\sinh \left(\nu_{n}\right)}{\left.\tilde{z}_{a}\right)} \frac{J_{0}\left(\nu_{n} r^{\prime}\right) J_{0}\left(\nu_{n} r\right)}{\nu_{n} J_{i}^{2}\left(\nu_{n} a\right)}
$$

for $\tilde{z}>z^{\prime}$, where the eigenvalues are still given by $E_{1}$. (13). This expression puts an inage charge both at the planc $\bar{z}=0$ and at the plane $\tilde{z}=\tilde{z}_{n}$, an anorle plane. It should be possible to conbine these Green functions for the gun region with the simpler open drift-tube expression of $\mathrm{Eq}$. (11). One could also use dilterent cadii in the two regions for the radial boundary conditions. The Green function for a cylindrical tube, closed al only one end, is ${ }^{10}$

$$
\begin{gathered}
\tilde{\Phi}\left(r, \tilde{z} ; r^{\prime}, \tilde{z}^{\prime}\right)=\frac{1}{\pi \epsilon_{n} a^{2}} \sum_{n=1}^{\infty} \frac{J_{0}\left(\nu_{n} r^{\prime}\right) J_{0}\left(\nu_{n} r\right)}{\nu_{n} J_{1}^{2}\left(\nu_{n} a\right)} \\
\times\left\{\begin{array}{ll}
\exp \left(-\nu_{n} \tilde{z}\right) \sinh \left(\nu_{n} \bar{z}^{\prime}\right) & \text { for } \tilde{z}^{\prime}<z \\
\exp p\left(-\nu_{n} \bar{z}^{\prime}\right) \sinh \left(\nu_{n} \tilde{z}\right) & \text { for } \bar{z}^{\prime}>\bar{z}
\end{array} .\right.
\end{gathered}
$$

The radial boundary conditions canse the infinite series in the potentials. Thus, another method that wonld certainly reduce the anmont of computer time would be to ignore the radial boundaries and use the free-space expression for the potential of a charge ring ${ }^{11}$

$$
\tilde{\Phi}\left(r, \tilde{z} ; r^{\prime} \tilde{z}^{\prime}\right)=\frac{1}{2 \pi^{2} \epsilon_{0} \tilde{r}_{1}} \Pi(\tilde{k})
$$

where

$$
\begin{gathered}
\tilde{r}_{1}^{2}=\left(z-z^{\prime}\right)^{2}+\left(r^{\prime}+r\right)^{2} \\
\tilde{k}=\frac{2 \sqrt{r} r^{i}}{\tilde{r}_{1}}
\end{gathered}
$$


and $\mathrm{K}(\mathrm{k})$ is the complete elliptic integral of the first kind. The advantage of this method is that the power series ${ }^{12}$ for the elliptic integrals is as short as the power series ${ }^{12}$ for a single Besscl function. The cathode boundary condition may be satislied with an inage ring. It is not too difficult to calculate the following fields from the potential ${ }^{11}$

$$
\begin{gathered}
\tilde{E}_{r}\left(r, \tilde{z} ; r^{\prime}, \tilde{z}^{\prime}\right)=\frac{1}{4 \pi^{2} \epsilon_{0} r \tilde{r}_{1}}\left\{K(\tilde{k})-\frac{r^{\prime 2}-r^{2}+\left(\tilde{z}-\tilde{z}^{\prime}\right)^{2}}{\tilde{r}_{1}^{2}} \frac{E(\tilde{k})}{1-\tilde{k}^{2}}\right\} \\
\tilde{E}_{2}\left(r, \tilde{z} ; r^{\prime}, \tilde{z}^{\prime}\right)=\frac{1}{2 \pi^{2} \epsilon_{0}} \cdot \frac{\tilde{z}-\tilde{z}^{\prime}}{\tilde{r}_{1}^{3}} \frac{E(\tilde{k})}{1-\tilde{k}^{2}},
\end{gathered}
$$

where $\mathrm{E}(\mathrm{k})$ is the complete elliptic integral of the second kind. As before, these Green functions may be Lorentz transformed from a static frame to the laboratory frame and integrated over a finite volume to remove the singularity at the source point, but this must be done mumerically.

Another method that has an exccllent chance of drastically reducing the computation time requireal for the space-charge fields is 1.0 use the Buncman last Fourier transform method that lias been modified by Vaughan ${ }^{13}$ for cylindrical coordinates. This method uses a moving grid that is one wavelength long to calculate the potential from all the charges at the grid points. The grid extends to a radial boundary and moves with the beam, so a rather small grid is used. The space-charge tields are assmmed to be periodic in the axial direction, but this assumption is good in the lasertron as the effect of one bunch on another is not very important. The computation time is expected to be much shorter than for the Green function method because of the $n \log n$, rather than $n^{2}$ dependence of the computation time on the number of particles. It is also worth noting that Vanghan has developed a fast simultaneous differentiation and interpolation routine INTRA ${ }^{14}$ that should save time in all the Green function calculations. Thie interpolation procedure in the Bessel function case is complicated and time consuming. With the introduction of the Buneman-Vaughan subrontine INT'RA, one could reduce the computer time by at least half because the potentials are simpler expressions than the fields, and there is only a single potential rather than two fields to calculate. 'The infinite series for the potential also converges faster than the lields because there is a factor of $\nu_{n}$ in the former denominator.

The most accurate method for calculating the space-charge fields is to solve the Maxwell equations with the moving bunch as a source as is done in MASK, ${ }^{15}$ Shintake's $\mathrm{FCl},{ }^{16}$ or Weiland's $\mathrm{BCl} .{ }^{17}$ All of these programs can take into account the real, complicated boundary conditions. Because FCI solves only for a single component of the vector potential, one expects that the $\mathrm{FCl}$ program would be smaller and faster than the three-field prograns. 


\section{ELECTROSTATIC FIELDS}

The electrostatic fields in the gim region are approximated in several ways. The simplest is to take the one-climensional expression

$$
E_{z}(z)= \begin{cases}-V_{a} / z_{a} & \text { for } 0 \leq z \leq z_{a} \\ 0 & \text { for } z>z_{a} \text { and } z<0\end{cases}
$$

The most accurate approximation is to run Iermannsfeldt's electron gun code ${ }^{5}$ for the artual lasertron geometry, but for a very small beam current, and to write the potential to a disk file. This data file is then reformatted with a simple program and used as input clata in the lasertron program.

Another method that has been programmed is to nse a spherical static field. This nethod is useful to determine a new geometry before using the Herrmannsfeldt program. In this case the axial static field is

$$
E_{z}(R, Z)=\frac{Q_{v}}{4 \pi \epsilon_{0}} \frac{\left(Z-Z_{v}\right)}{\left[R^{2}+\left(Z-Z_{v}\right)^{2}\right]^{3 / 2}}
$$

and the radial siatic field is

$$
E_{r}(R, Z)=\frac{Q_{v}}{4 \pi \epsilon_{0}} \frac{R}{\left[R^{2}+\left(Z-Z_{v}\right)^{2}\right]^{3 / 2}}
$$

where $Q_{v}$ and $Z_{v}$ are parameters that are chosen to match the real ficld distribution.

Another possible method is to approxinate the static potential in the gun region by a few terms of the series

$$
\Phi(R, Z)=\sum_{j}^{I S T A T} A_{j} J_{0}\left(T_{j} R\right) \sinh \left(T_{j} Z\right),
$$

where $\Phi$ is normalized such that $\Phi\left(0, Z_{a}\right)=1$. The electric fields are then

$$
E_{r}(R, Z)=\sum_{j=1}^{I S T A T} A_{j} J_{1}\left(T_{j} R\right) \operatorname{sinl} l_{1} T_{j} Z
$$

and

$$
E_{z}(R, Z)=\sum_{j=1}^{I S T A T} A_{j} J_{0}\left(T_{j} R\right) \cosh T_{j} Z,
$$

where ISTAT is the maximum number of terms used in the approximation. These last two equations have not yet been programmed because it will be difficult to relate the $A_{j}$ 's and $\mathrm{T}_{j}$ 's to the electron gun geometry. 


\section{STATIC MAGNETIC FIELDS}

The static focus fieid has been assumed to be piecewise linear, and it may have 10 breakpoints from the cathode to the end of the ontput cavity. 'The axial field is constant before tine first breakpoint and after the last breakpoint. Between breakpoints, the fields on the ith electron that is to the jth breakpoint are

$$
B_{z i}(R, Z)=B_{z j}+\left(Z_{i}-Z_{b j}\right) S L O P E_{j}
$$

and

$$
B_{r_{2}}(R, Z)=-0.5 S L O P E_{j}
$$

where $S L O P E_{j}$ is $d B_{z} / d Z$. To use this option, a small talsle of the breakpoint fields and positions are read as input data.

A second option, which las not yet been incorporated into the code, is to read a clat a file of $B_{r}, B_{z}$ fields that have been computed with PUISSON, a magnetic field solver program. With this metliod, lerromagnetic components are allowable, but one has to make POISSON runs whenever the ferromagnetic components are changed.

A third option that has been used in the past is to evaluate the fields of $\mathrm{j}$ ideal current loops over a magnetic gricl and then to interpolate the grid fields to find the fields at the particle positions. 'The magnetic ficlds are ${ }^{18}$

$$
B_{r}(r, z)=\sum_{j} \frac{\mu_{0} i_{j}\left(z-z_{j}\right)}{2 \pi r r_{1 j}}\left\{\left[\frac{r_{j}^{2}+r^{2}+\left(z_{j}-z\right)^{2}}{r_{1 j}^{2}}\right] E\left(k_{j}\right)-K^{2}\left(k_{j}\right)\right\}
$$

and

$$
B_{i}(r, z)=\sum_{j} \frac{\mu_{0} i_{j}}{2 \pi r_{1 j}}\left\{\left[\frac{r_{j}^{2}-r^{2}-(z j-z)^{2}}{r_{1 j}}\right] E\left(k_{j}\right)+K\left(k_{j}\right)\right\},
$$

where

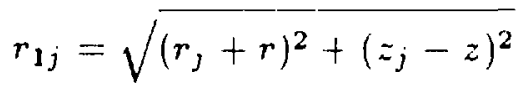

and

$$
k_{j}^{2}=4 r r_{j} / r_{i j} .
$$

\section{RF OUTPUT CAVITY FIELDS}

There are three methods of calculating the output cavity fields that may be used in the program. The most realistic is to use output from the SIIPERFISH code. The $B_{\phi}$ conponent for a single eigentuode of a given cavity is calculated with SUPERFISH for the empty cavit $y$, and this field is written as a dala file that is read by the lasertron program. These data are interpolated and the appropriate derivatives are taken to find the fields for each electron in the ontput section for each time step. The amplitude and phase of these fields may be set by either of the methods that are discussed below. 
The simplest method of estimating the output lields is to use the planar gap approxinnation

$$
E_{z}(r, z)=V_{r f} / D_{r f} \cos \left(\omega t+\phi_{r f}\right),
$$

where $V_{r f}, D_{r f}$, and $\phi_{r f}$ are the gap voltage on the axis, the leingth of the output region in which there is field, and the phase angle of the onlput fields, respectively.

The third option for the output fields is to use a few ternus of the scries

$$
E_{z}(r, z)=\frac{V_{r f}}{D_{r f}} \sum_{m=1}^{M I R F} A_{r f}(m) \frac{I_{0}\left(\gamma_{m} r\right)}{I_{o}\left(\gamma_{m} a\right)} \cos \left[k_{m}\left(z-z_{c}\right)\right] \cos \left(\omega t+\phi_{r f}\right) .
$$

The other fielcl components are

$$
E_{r}(r, z)=-\frac{V_{r f}^{r}}{D_{r f}} \sum_{m=1}^{N i R F} \frac{A_{r f}(m) k_{m} I_{1}\left(\gamma_{m} r\right)}{\gamma_{m} I_{o}\left(\gamma_{m} a\right)} \sin \left[k_{m}\left(z-z_{c}\right)\right] \cos \left(\omega t+\phi_{r f}\right)
$$

and

$$
B_{\phi}(r . z)=-\frac{V_{r f}}{D_{r f}} \sum_{m=1}^{N R F} \frac{\omega A_{r f}(m) I_{1}\left(\gamma_{m} r\right)}{c^{2} \gamma_{m} I_{o}\left(\gamma_{m} \alpha\right)} \cos \left[k_{m}\left(z-z_{c}\right)\right] \sin \left(\omega t+\phi_{r f}\right)
$$

where

$$
\begin{gathered}
k_{m}=\pi(2 m-1) / D_{r f}, \\
\gamma_{m}^{2}=k_{m}^{2}-(\omega / c)^{2},
\end{gathered}
$$

and $z_{r}$ is the axial location of the gap cruter.

$\mathrm{W}$ ith all three methods of calculating the ontput-gap fielcls, the amplitude and the phase of these fields remain to be chosen. The simplest inethod is to adjust these values to obtain the maximun energy conversion efficiency, but the corresponding cavity inpedance may not be physically reaiizable. 'The self-consistent method of calculating the ga! voltage and phase is as follows. ${ }^{2}$ The cavity voltage is the voltage on the axis,

$$
V_{r f}(t)=\int_{-\infty}^{\infty} \vec{E}_{c o n t y} \cdot d \hat{z}
$$

but this voltage is also a solution of

$$
V_{r f}=i_{\text {ind }} Z_{c a v}
$$

where $Z_{\text {cav }}$ is the cold-cavity impedance

$$
1 / Z_{c a v}=1 / R_{s h}+j\left(f / f_{0}-f_{0} / f\right) /\left(R_{s h} / Q\right)
$$


$R_{s h}$ is the cavity shmnt impedance, $Q$ is the loaded $Q$ of the emply cavity, and $f_{0}$ is the resonant frectuency of the output cavily. Thle current induced in the output circuit by the beran is given by the Rano theorem,

$$
i_{\text {ind }}(t) V_{r f}(t)=\int_{V} \vec{J} \cdot \vec{E}_{c a v t y} d v,
$$

where the integral is over the output cavity volume. The Fourier component of the induced current is given by

$$
i_{i n d_{n}}=1 / f \int_{3}^{1 / f} i_{\text {ind }}(t) \exp (j 2 \pi f n t) d t .
$$

The higher components of Eq. (60) are not used at present. They are only required for harmonic cavities or cavities for which the impedance is important at more than one harmonic.

With the self-consistent method of the onl.put voltages and phases, the calculations begin with a cavity impedance, baserl on realizable cavities. Next, a first approximation to the gap phase and amplitude is made, and the particles are tracked across the output region. Whien all the particles leave the gap, the induced current integral is complete, and the gap phase and voltage are recalculated. A relaxation parameter is used to estimate the next pair of voltages and phases, and the output cavily dynanics are redone until convergence criterion is satisfied. Three to six iterations are usually required for one part in 1000 self-consistency.

\section{DC TO RF CONVERSION EFFICIENCY}

The simplest procedure to estimate the do to rf conversion efficiency is to ignore the output gap and calculate the fundamental harmonic current and the axial momentum spread in the beam at the location of the center of the output gap. If a gap were correctly placed and coupled to the bunched beam, Mihran ${ }^{19}$ has shown that the quantity

$$
M F=\frac{i_{1}}{2 I_{0}} \frac{\left(\gamma v_{z}\right)_{s i o w}}{\left(\gamma v_{z}\right)_{a v g}}
$$

is a good estimate of the interaction efticiency. $I_{11} \mathrm{Eq} . \quad(61), i_{1} / I_{0}$ is the first Fourier component of the bean current, and the axial moment un is evaluated both for the slowest electron and for the average electron.

Rather than use the merit-figure approximation, it is more accurate to actually calculate the electron dynamics through the oulput gap with realistic, self-consistent gap fields and to estimate the efficiency as

$$
\eta=\frac{1}{N_{z} N_{r}\left(\gamma_{0}-1\right)} \sum_{i}\left(\gamma_{i}-1\right)
$$


where $\gamma_{0}$ is the relativistic factor for the dc anode voltage. This efficiency is the fraction of the kinetic energy that is transferred to the mirrowave fields. Some of this field energy is then lost as onmic heating of the output cavity, but this is a very small fraction for high out put power.

\section{THE COMPUTER PROGRAM}

A computer program lias been written in FUK'TRAN to solve the equations presented above. With the Euler method, the velocities are stepped forward in time, and the trapezoidal method is used to increment the positions. In the gun region, a 1.0-ps time step usually is a good value. The rf time step must generally be about $1^{\circ}$ of if phase, so it depends on the frernency. The program is written in a modular fashion, so it can be altere $^{-1}$ as the recutirements change. The program is interactive, bitt it requires about 10 data files to produce a good simulation with accurate $\mathrm{dc}, \mathrm{rf}$, magnetic, and space-charge fields. Output dala hles are written for the code DESSIN,${ }^{20}$ which produces the graphical output.

\section{MERIT-FIGURE RESULTS}

The electron dynamics of the lasert ron is very similar to that of the microwave triode, in that the bunching is very good initially and it grows worse as time goes on. 'The general conclusion is that the lasertron is an excellent nicrowave device at the lower frequencies and that it is more difficuit to obtain good efficiency as the frequency is increased. High acceleration gradients improve the conversion efficiency at any frequency. In Fig. 2, the merit figure is plotted versus the fraction of the maximum charge extracted per pulse, $q_{\max }$, where

$$
q_{\text {max }}=\pi r_{c}^{2} \epsilon_{0} E_{a} / d,
$$

$E_{a}$ is the acceleration field at the cathode, $r_{\mathrm{c}}$ is the cathode radius, and $d$ is the anodecathode spacing. When a charge of $q_{\max }$ is emitted in a bunch, the acceleration field at the cathode is completely cancelled by the sinplest approximation to the space-charge field. The calculations of Fig. 2 were made with one-dinensional acceleration fields, no rf output-gap fields, and the Bessel-function space-charge fields. The cathode radius is $15 \mathrm{~mm}$, the anode is $30 \mathrm{~mm}$ from the cathode, the drift tunnel radius is $20 \mathrm{~mm}$, and the voltage is $300 \mathrm{kV}$. The average current is $187.76 \mathrm{~A}$ at $q_{\max }=1$, and it is proportional to $q_{\text {max }}$. The other curve on the figure is the $B_{z}$ field (in gauss) that was required to constrain the beam within $20.0 \mathrm{~mm}$. The axial magnetic field starts out at the plotted value at the cathode and increases to twice the cathode value at $65 \mathrm{~mm}$, where the center of the output gap is located. The frequency is $3 \mathrm{GHz}$, and 3 radial and 16 axial subdivisions are used in the calcul= ions. The electron pulse length at the calhode is $60 \mathrm{ps}$. The predictions are very encouraging because the case for a fraction of 0.6 , for exanple, indicates an efficiency of $86 \%$ and an output power of $29 \mathrm{MW}$ with only a $900-\mathrm{G}$ peak magnetic confining field. The magnetic fields may be doubled to account for the output gap fields, but they remain low, partly because of the relatively low current for the voltage. 


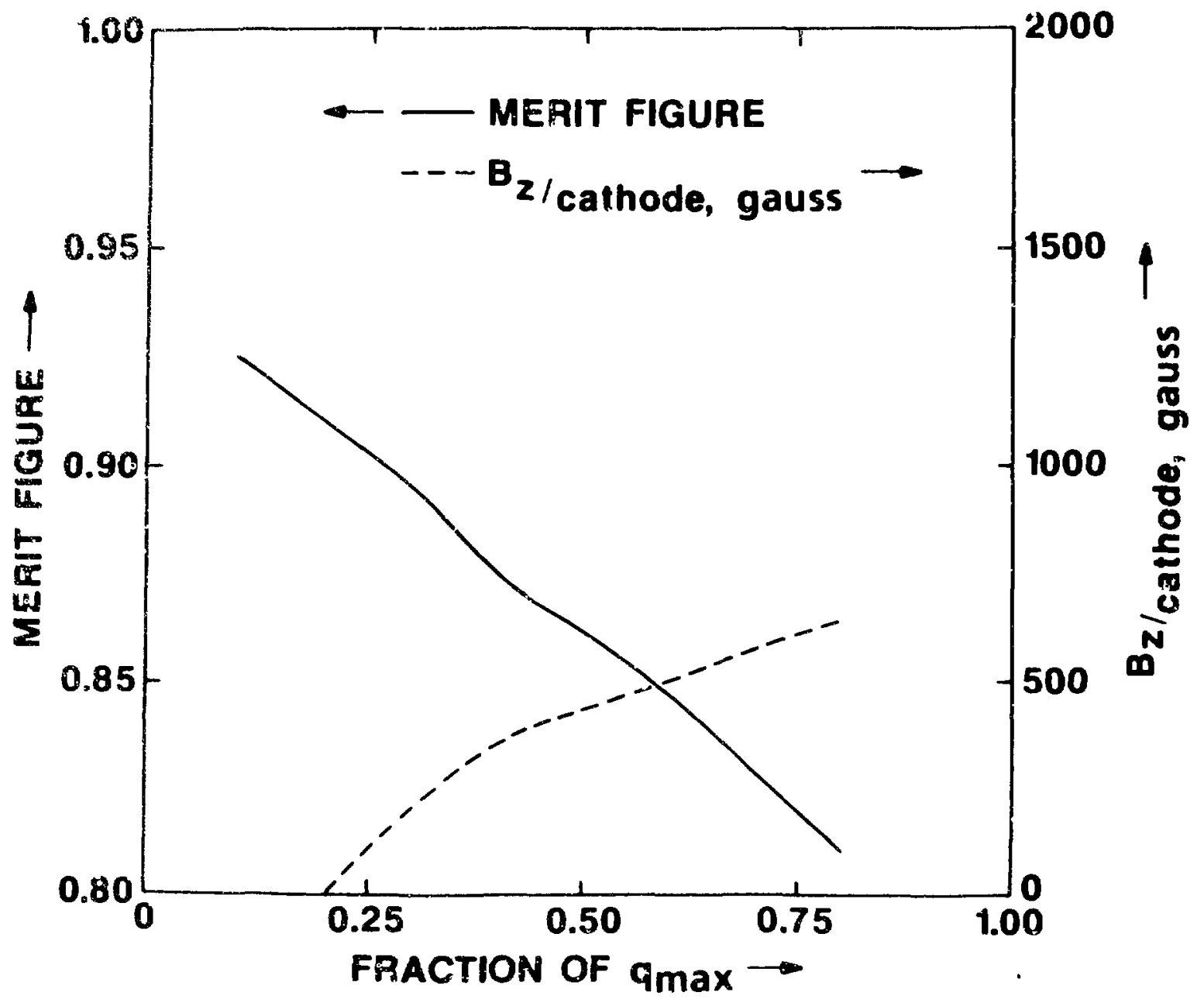

Fig. 2. Merit-figure estimate of efficiency and magnetic focus field versus fraction extracted of $q_{\max }$ at $3 \mathrm{GHz}$. Planar acreleration fields, Bessel function space-charge fields, $r_{\mathrm{c}}=15$ $\mathrm{mm}, V_{0}=300 \mathrm{kV}$, anode cathode distance $=30 \mathrm{~mm}$.

To show the effect of frequency, the above calculations were repeated for $6 \mathrm{Gillz}$, with only the cathode pulse length changed to $30 \mathrm{ps}$. The average and the peak currents are now twice as much for the same emitted charge fraction, and the required focus fields are much higher. The results are shown in Fig. 3. Note that the slope of the merit figure versus emitted charge fraction is about twice as much at 6 (iHz as at 3 Cillz. The current for the critical charge is now $375.5 \mathrm{~A}$. The results are still very encouraging because, at a fraction of 0.6 , the efficiency is $71.5 \%$ wilh in output power of $48.4 \mathrm{MW}$ and a peak magnetic field of $2400 \mathrm{G}$. 


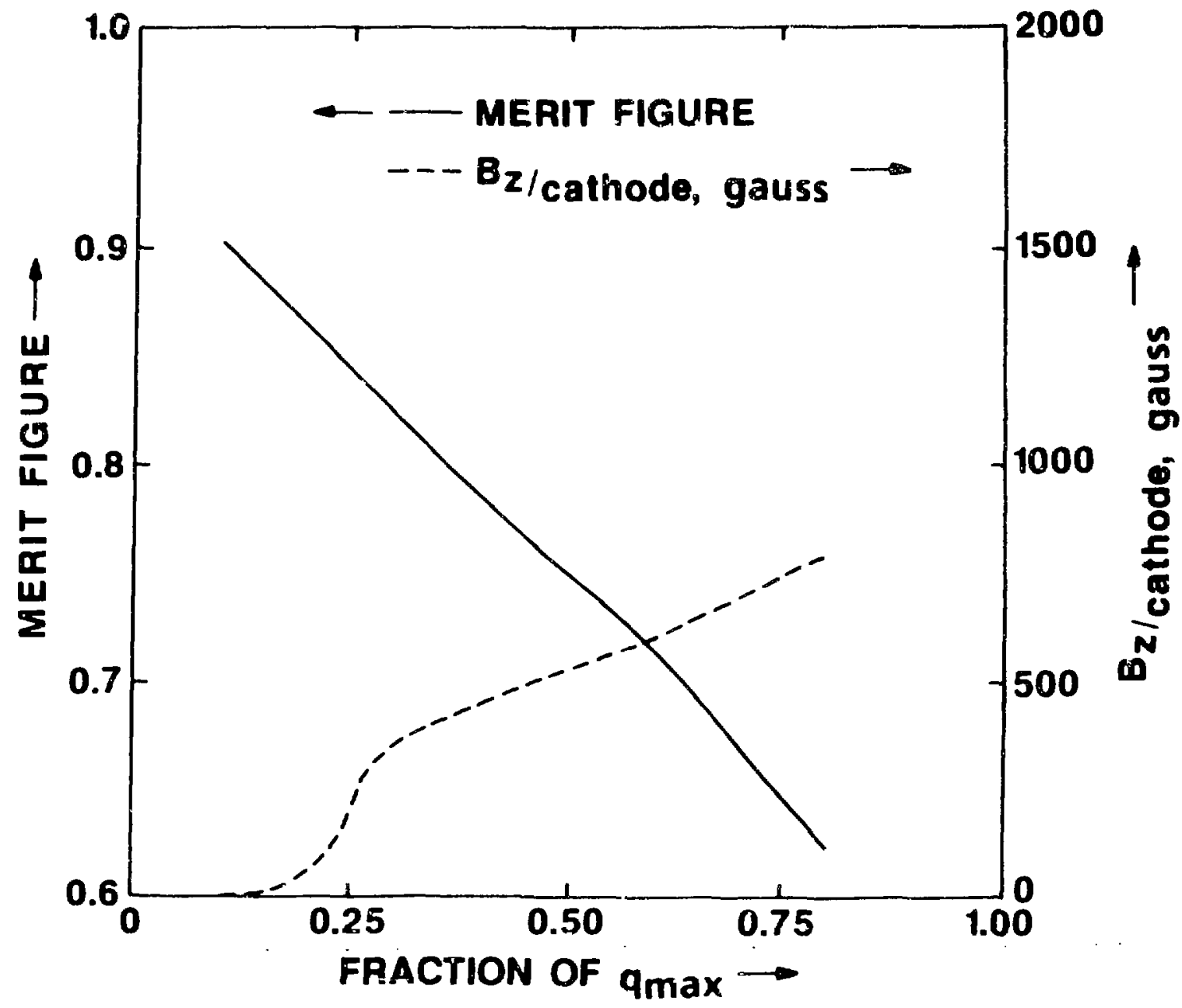

Fig. 3. Merit-figure est imate of efficiency and magnetic forus field versus fraction extracted of $q_{m a x}$ at $6 \mathrm{GiHz}$. Planar acceleration fields, Bessel function space-charge fields, $r_{c}=$ $15 \mathrm{~mm}, V_{0}=300 \mathrm{kV}$, anode cathode distaisce $=30 \mathrm{~mm}$.

\section{COMPARISON OF OUTPUT WITH PREVIOUS PROGRAMS}

The first case studied is the one-dimensional diode region, which was also studied by Shintake. ${ }^{16}$ The diode has a $30-\mathrm{mm}$ anode/catlode spacing, and the beam has a $30-\mathrm{mm}$ radius. The anode voltage is $300 \mathrm{kV}$, and the laser light pulse is $35 \mathrm{ps}$ long. Shintake presents two cases, 10 and $250{ }_{11 C} \mathrm{C}$, with the latter being the charge limit for this geomet ry. The $10-\mathrm{nC}$ case corresponds to only 0.04 of the critical charge; hence the space-charge forces are very low, and this code gives the same results as Shintake's. The high spacecharge case has the emitted charge equal to the critical charge, and it is FUNCell beyond the maximum efficiency case. The results with the Bessel function space sparge are shown in Fig. 4-a, and the results with the two-dimensional simplified space charge are show: in Fig. 4-b. The Bessel function case shows niore radial and axial space-charge effects than do Shintake's results, but there is a general agreement. The major differences are due to the inclusion of the cathode image ficlds in Shintake's work. The two-dinensional simplified 
space charge do include the cathode inage ficlds, and the agreement is much betler with Shintake in this case. It secms clear that the present corke would be much improverl if the two-dimensional simplified space-charge forces were used in the gun region and the Bessefunction space charge were used in the drift and ontput regions. 'This modification has been made and is being tested now.
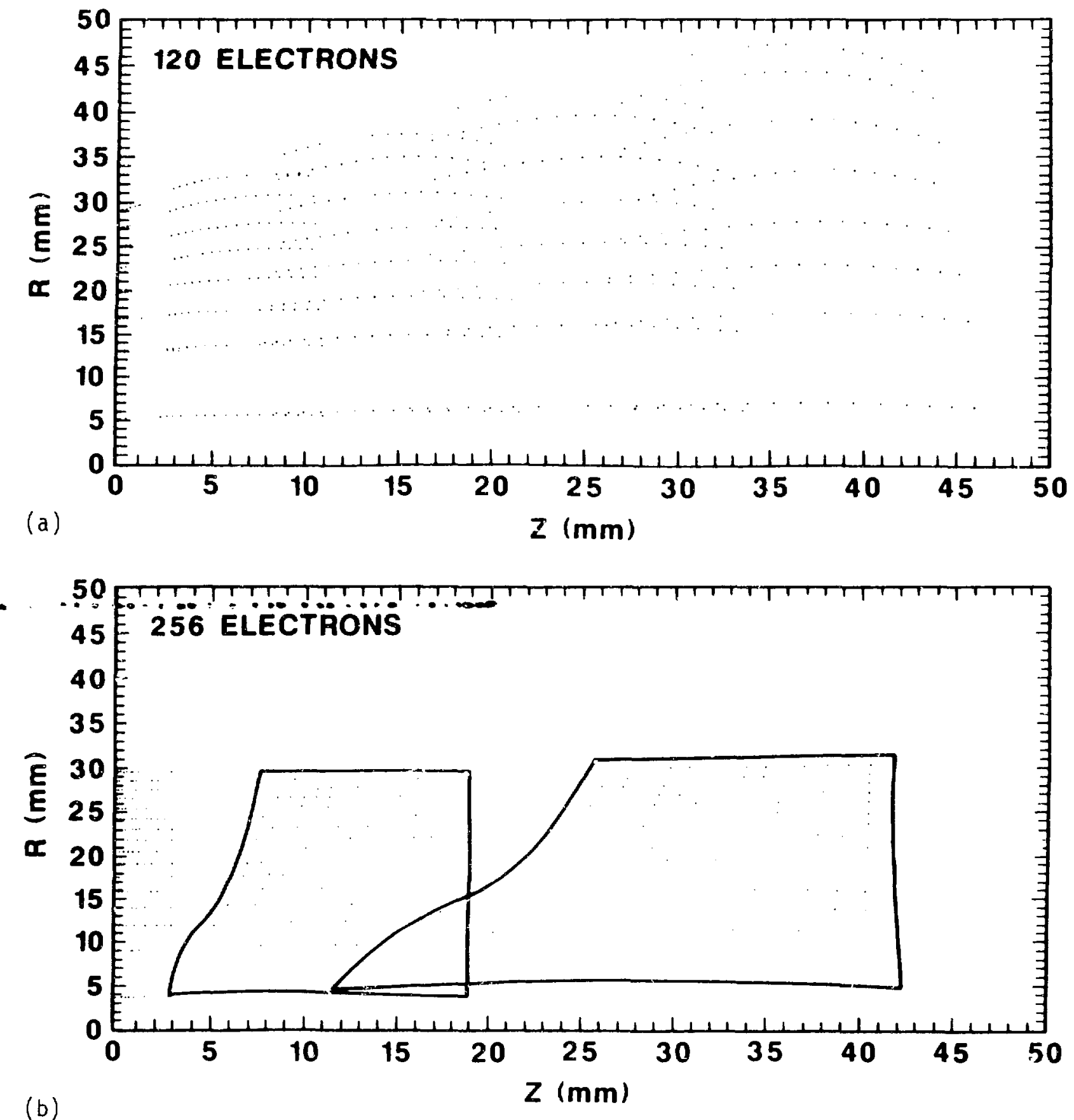

Fig. 4. Snapshots of the KEK lasertion at $300 \mathrm{kV}, 250 \mathrm{nC}$, scale in $\mathrm{mm}$.

(a) Bessel function space charge with times of $50,100,150,200$, and $250 \mathrm{ps}, 128$ particles.

(b) Two-dimensional space charge witin times of 50, 150, and $250 \mathrm{ps}, 256$ particles. 
The single oulput cavity SLAC protoiype lasertron has also been studied with this corle. The results are not complete at the time of !his report, but the preliminary results are in general agreenent; frowever, the present code sliows larger radial space-charge forces than MASK does. I'he differences can be explained by the methods of truncating the spacecharge forces when particies ovestap. In the present work, the axial forces are truncated to zero as the cliarges approach one another, hut the radial forces approach a constant, rather large value for zero charge separation. The usual plasma-physics approximation is to trumcate both of these forces to zero for small particle separations. This approximation can be easily put into the present code if the experiments indicate that it is desirable to do so.

\section{CALCULATIONS ON THE 6-GHz ORSAY PROTOTYPE}

The first detailed calculation made with this corle is for the 6-GIIz lasertion designed at Orsay for linear collider applications. A sketch of this !nsertron is shown in Fig. 5. The electron gın was Jesigned with Hermannsfeldt's code; then the current was reduced to

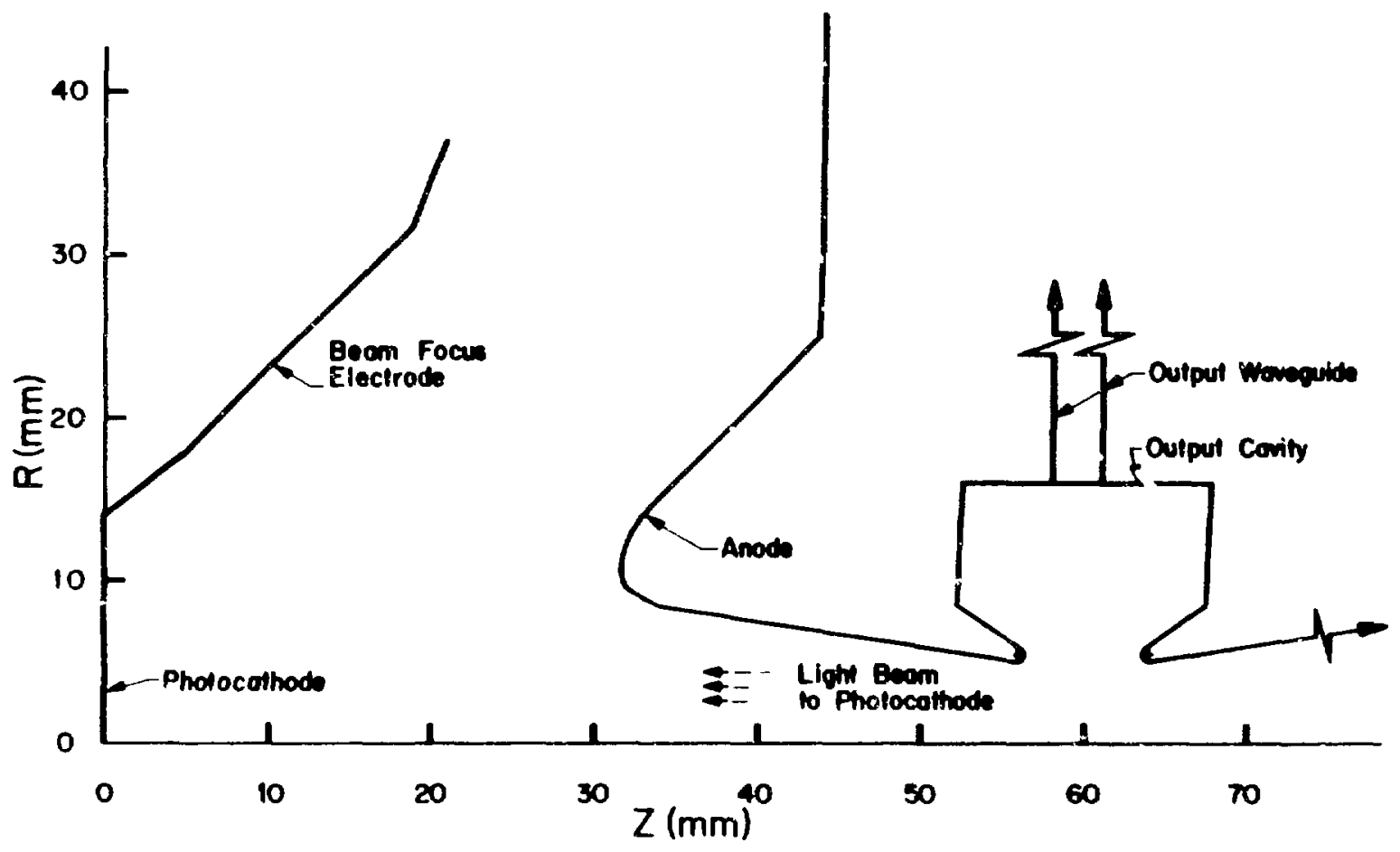

Fig. 5. Sketch of the microwave geometry for the 6-GIIz Orsay prototype lasertron. 
almost zero and the staic fickls calculated. The SUPERFISII code was used to design an output cavity, sund the $H_{\phi}$ table in $r, z$ was calculated and used as input data. The first results are that the de fields in this design are not correct for good bean transmission in the pulsed mode. 'The gun produces gond trajectories for a continuous beam but very poor trajectories in the lasertron mode, with 20 to $40 \%$ interception at the anode. When the emission surface is made smaller, the sane electrodes produce a much nucre uniform field over the cathode surface, but the current is smaller. With the smaller cathodes, excellent efficiencies are calculated. Figure 6-a shows the overall trajectories for the prototype lasertron with a $7-1 m m$ cathode sinnulated by 2 rings and only 16 total electrons. The anode voltage is $300 \mathrm{kV}$, and the beam clearly is too close to the drift tube, but only one electron is intercepted and the efficiency is $70.4 \%$. An axial magnetic field of $250 \mathrm{G}$ at the cathode rises to 800 ) ( $80 \mathrm{~mm}$ away. The cutput cavity voltage is $350 \mathrm{kV}$, and the phase is 2.5 radians. The self-consistent method was not used in this calculation. The beam current is only $6.0 \mathrm{~A}$ on the average, but this lasertron will produce $1.27 \mathrm{MW}$ at 6 GHz with a very respectable efficiency. 'T'he ontput cavity dynamics are shown in Fig. 6-b, where the radial scale is enlarged, and the electrons are shown every $100 \mathrm{ps}$.

Note that the beam initially spreads out because the magnetic focusing is ineffective near the cathode. The same simulation has been made with 4 rings and a total of 32 electrons, and the results are shown in Fig. 7 . 'The calculated efficiency is still $70 \%$, essentially the same as with 16 electrons. The CPU time for simulation of the 16-electron case is only $28 \mathrm{~s}$; thus, many changes can be made in a. few hours of time with the computer. The CPU time for the 32-electron: simulation is $130 \mathrm{~s}$ because the computation time varies with the square of the number of electrons. A third set of calculations on the prototype was made with 12 -A peak current and the beam voltage at $300 \mathrm{kV}$. A peak efficiency of $68.3 \%$ was found with all the same parameters as the 6-A case, except that the catliode focus field was increased to $350 \mathrm{C}$, and the focus field at $80 \mathrm{~mm}$ was increased to 1600 C. This efficiency corresponds to an ont.jut power of $2.46 \mathrm{MW}$, and still only $20 \%$ of the maximum available charge is taken from the cathode. When the current was doutbled again, to $24 \mathrm{~A}$, an optimum efficiency of $65.5 \%$ was found with a cathode field of $700 \mathrm{G}$, and an $80-\mathrm{mm}$ field of $2300 \mathrm{G}$. 'The output power is $4.72 \mathrm{MW}$, and all the remaining parameters are the same as in the previous calculations. This output power is quite interesting, and the required shunt impedance in the output cavity is a factor of 4 lower than in the 6-A case; therefore, the nodified design is easier to realize. The trajectories for the 24-A case are shown in Fig. 8. The space-cliarge forces are very large in the output cavity, and the beam suddenly goes from converging to diverging right at the center of the output gap.

More simulations with the self-consistent output field method and more particles have to be made, but the results so far indicate that the protolype slonild be capalsle of high efficiency at $6 \mathrm{GHz}$, and that it would work even better at lower frequencies. These calculations also show that the optimal gun design must have a flatter cathode fieldforming electrode than the classical Pierce gun, anl it seems very difficult to design any convergence into the beam. With some cathode matcrials, it. will be possible to use a curved cathode; this should help the field unifornity proble ms at the catliode. T'he code has now been modified to handle curved cathodes, and the initial calculations are encouraging. 


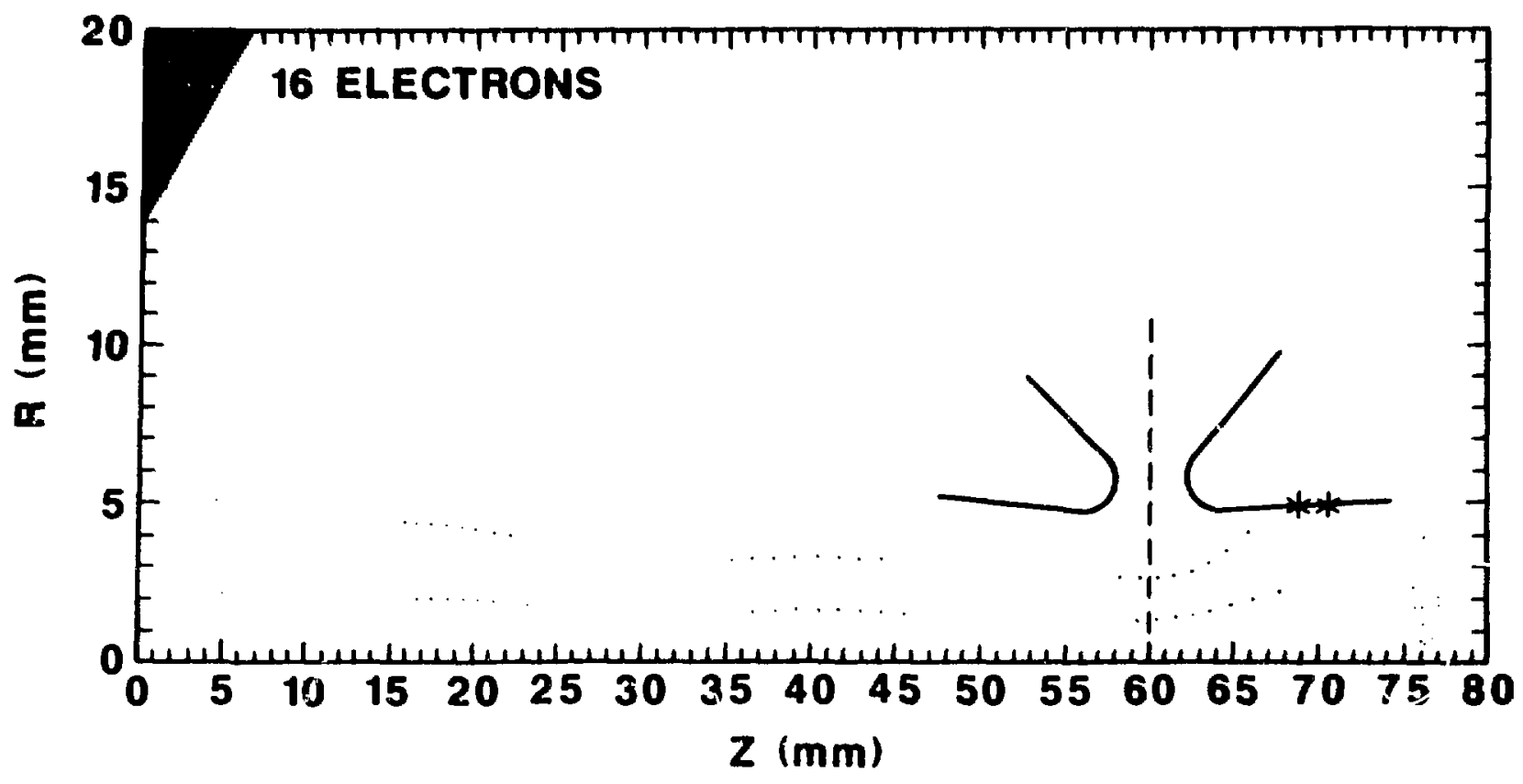

TIME (ps) $=100200300400500$

(a)

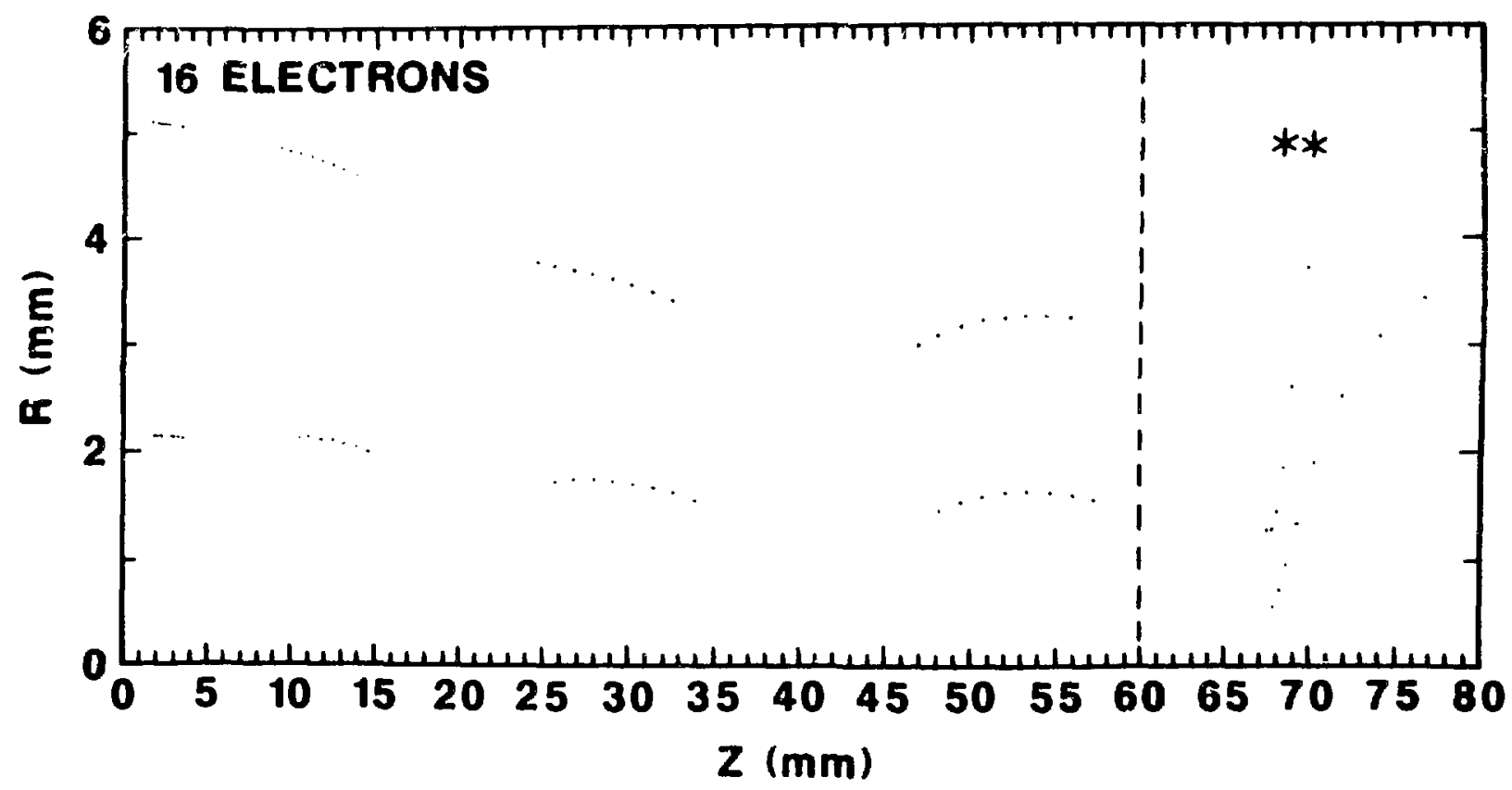

(b)

Fig. 6. Electron trajectories for the prototype with $r_{c}=15 \mathrm{~mm}, 6 \mathrm{Gllz} V_{0}=30 \mathrm{kV}$, $V_{r f}=350 \mathrm{kV}$, and $I_{a v g}=6.0 \mathrm{~A}$. Sixteen particles. 


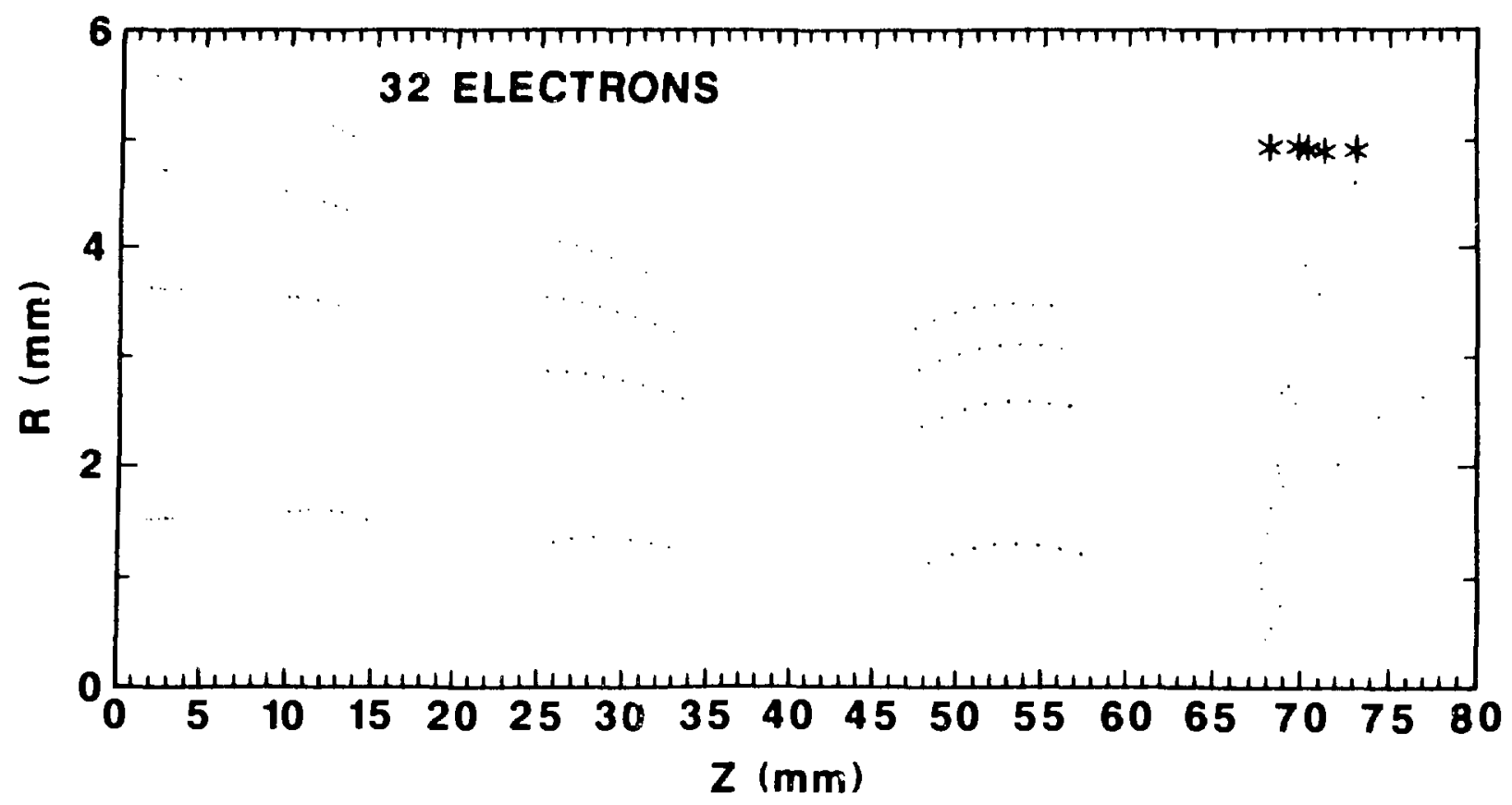

Fig. 7. Flectron trajectories for the prototype with $r_{c}=15 \mathrm{~mm}, 6 \mathrm{GHz}, V_{0}=300 \mathrm{kV}$, $V_{r f}=350 \mathrm{kV}$, and $I_{a v g}=6.0 \mathrm{~A}$. Thirty-two particles.

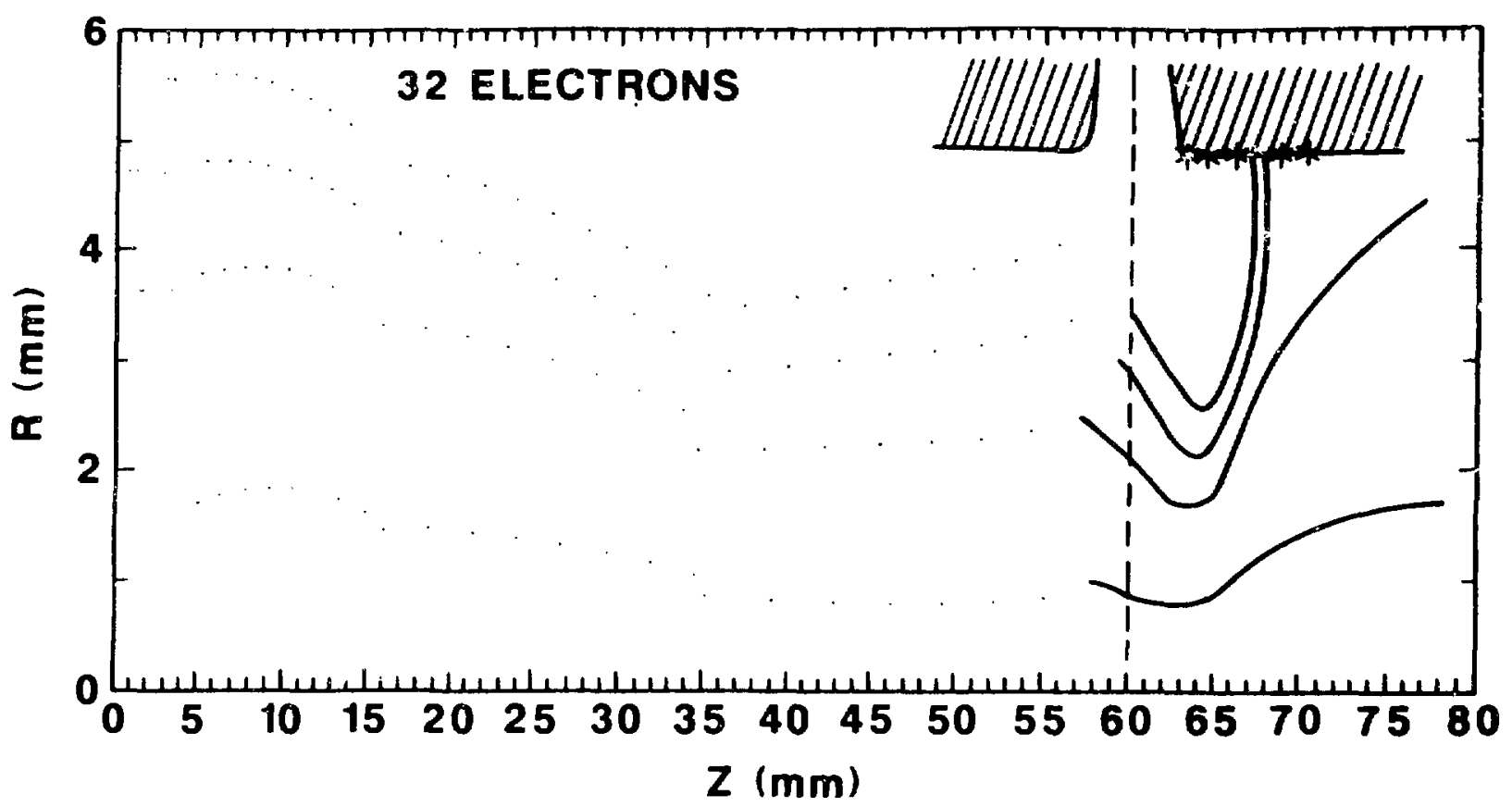

Fig. 8. Electron trajectories for the prototype with $r_{c}=15 \mathrm{~mm}, 6 \mathrm{GIIz}, V_{0}=300 \mathrm{kV}$, $V_{r f}=350 \mathrm{kV}$, and $I_{a v g}=24 \mathrm{~A}$. 'Thirly-two particles. 


\section{CONCLUSIONS}

A ring morled theory for the lasertron has been written and programmed in FORTRAN. The code is self-consistent and relativistically correct to first order in $\mathrm{v} / \mathrm{c}$. The particle motion is followed from a photocathode, through an acceleration region, and through an output gap to a collector. Preliminary checks with previous work show good agreement, and calculations on the prototype lasertron to be constructed at Orsay indicate that efliciencies of over $65 \%$ should be available even at $6 \mathrm{GHz}$. At lower frequencies, high powers of over $50 \mathrm{MW}$ should be possible, and the efficiency should rise above $80 \%$, allhough it is likely that double or even triple output-gap cavities will be necessary lo obtain the highest efliciencies. The corle has recently been modified to include curved cathodes, the ability to model the time structure of the laser pulse, and to use different space-charge approximations in the different regions of the clevice. The next improvements will be the use of multiple bunches to follow the evolution to stearly state and to include multiple output gaps. More comparisons witl the past codes nust be made, and comparisons with experimental data will be made when they become available.

The calculations already made show that the lasertron is capable of generating high output powers at very good efficiency up to at least $6 \mathrm{GHz}$. Both the peak output power and the conversion efficiency increase as the operating frequency is decreaseci.

\section{ACKNOWLEDGMENTS}

The primary author (PJT) wishes to thank his supervisors at Los Alamos, especially R. A. Jameson and S. O. Scluriber, for permission to take a sabbatical leave at the University of Paris to work on the lasertron. Both anthors thank M. Davier, J. Le Duff, and P. Brunet for their euthusiastic support of the project. The authors also thank A. Dubrovin for the fine graphics program that he developed for this project.

\section{REFERENCES}

1. P. J. Tallerico and B. E. Carlsten, "Computer Modeling of the Klystron," IEEE Trans. Nucl. Sci. $\mathbf{3 0}$ (4), 2170 (1983).

2. P. J. Tallerico and B. E. Carlsten, "Self-Cionsistent Klystron Simulations," IEEE Trans. Nucl. Sci. 32 (5), 2837 (1985).

3. B. E. Carlsten, "A Self-Consistent Numerical Analysis of Klyst.rons Using Large-Signal Beam-Wave Interaction Simulations," Ph.D. thesis, Dept. of Elec. Eng., Stanford Universily (1985).

4. J. D. Jackson, Classical Electrodynamics (4), 2nd Ed., (John Wiley and Sons, New York, 1975), p 572.

5. W. B. Hermannsfeldt, "Electron Trajectory Program," Stanford Linear Accelerator Center internal report SLAC-166 (1973). 
6. K. Halibach and R. Holsinger, "SUPERFISIl - A Compnter Program for Evalualion of rf Cavilies with Cylindrical Symmetry," Particle Accelerators, 7, 213 (1976).

7. J. L. Warren, G. P. Boicourt, M. T. Menzel, G. W. Rodenz, and M. C. Vasquez, "Revision and Documentation of the Standard Version of the POISSON Codes," IEEE Trans. Nucl. Sci. 32 (5), 2870 (1985).

8. P. J. Tallerico and J. E. Rowe, "Relativistic Effects in the Travelling Wave Amplifier," IEEE Trans. Electrous Devices ED-17 (T), 549 (1970).

9. W. R. Smythe, Static and Dynamic Electricity, (McGraw-Iill Book Company, New York, 1950).

10. R. B. Miller, An Introduction to the Physics of Intense Charged Particle Beams, (Plemun Press, New York, 1982).

11. E. Durand, Electrostatique, Tome 1, Les Distributions, (Masson et Cie., Paris, 1965).

12. M. Abramowitz and I. A. Stegın, Handbook of Mathematical Functions, (National Bureau of Standards, Applied Malhenalical Series 55, June, 1964).

13. J. R. M. Vaughan, "The Space-Charge Potential in a Cylindrical Tunnel," IEEE Trans. Electron Devices ED-26 (10), 1649 (1979).

14. J. R. M. Vanglian, "The RF Vector Potential in a Gapped Tunnel," IEEE Trans. Electron Devices ED-26 (10), 1642 (1979).

15. K. R. Eppley, "Optimization of a I,asertron Double Output. Cavity," Stanford Linear Accelerator Center note SLAC/AP-48 (1986).

16. T. Silial ake, "FCI-Field (harge Interaction Program," KFK (National Laboratory for High Energy Physics, 'TSUKUBA, Japan) Preprint 84-14 (1984).

17. T. Weiland, "TBCI and IRMT's - New Computer Codes for Wake Field and C'avity Mode Calculations," IEEE. 'T a aus. Nucl. Sci. NS-30, (4), 2849 (1983).

18. R. F. Harrington, Introduction to Electromagnetic Engineerit:g, (McGraw Hill, New York, 1958).

19. T. G. Milıran, "The Effect of Drift. Length, Beam Radins anrl Perveance on Klystron Power Efficiency," IEEE Trans. Electron Devices ED-14 201, (1967).

20. A. Dubrovin, "Craphisme du Lasertron et Commentaires Sur la Dynamique d" Programme 'Ring' de Simulation," Laboratoire de l'Accélérateur Linéaire, (L.A.L.) Unjversité Paris-Sud, 91405 Report SERA 86-162, Orsay, (1986). 